\title{
The face never lies: facial expressions and mimicry modulate playful interactions in wild geladas
}

\author{
Alessandro Gallo ${ }^{1,2} \cdot$ Anna Zanoli $^{1} \cdot$ Marta Caselli $^{1} \cdot$ Ivan Norscia ${ }^{1,3}$ (D) Elisabetta Palagi ${ }^{3,4}$ (D) \\ Received: 9 August 2021 / Revised: 31 December 2021 / Accepted: 4 January 2022 / Published online: 14 January 2022 \\ (c) The Author(s) 2022
}

\begin{abstract}
Play fighting, the most common form of social play in mammals, is a fertile field to investigate the use of visual signals in animals' communication systems. Visual signals can be exclusively emitted during play (e.g. play faces, PF, contextdependent signals), or they can be released under several behavioural domains (e.g. lip-smacking, LS, context-independent signals). Rapid facial mimicry (RFM) is the involuntary rapid facial congruent response produced after perceiving others' facial expressions. RFM leads to behavioural and emotional synchronisation that often translates into the most balanced and longest playful interactions. Here, we investigate the role of playful communicative signals in geladas (Theropithecus gelada). We analysed the role of PF and LS produced by wild immature geladas during play fighting. We found that PFs, but not LS, were particularly frequent during the riskiest interactions such as those including individuals from different groups. Furthermore, we found that RFM $(\mathrm{PF} \rightarrow \mathrm{PF})$ was highest when playful offensive patterns were not biased towards one of the players and when the session was punctuated by LS. Under this perspective, the presence of context-independent signals such as LS may be useful in creating an affiliative mood that enhances communication and facilitates most cooperative interactions. Indeed, we found that sessions punctuated by the highest frequency of RFM and LS were also the longest ones. Whether the complementary use of PF and LS is strategically guided by the audience or is the result of the emotional arousal experienced by players remains to be investigated.
\end{abstract}

\section{Significance Statement}

Facial expressions and their rapid replication by an observer are fundamental communicative tools during social contacts in human and non-human animals. Play fighting is one of the most complex forms of social interactions that can easily lead to misunderstanding if not modulated through an accurate use of social signals. Wild immature geladas are able to manage their play sessions thus limiting the risk of aggressive escalation. While playing with unfamiliar subjects belonging to other groups, they make use of a high number of play faces. Moreover, geladas frequently replicate others' play faces and emit facial expressions of positive intent (i.e. lip-smacking) when engaging in well-balanced long play sessions. In this perspective, this "playful facial chattering" creates an affiliative mood that enhances communication and facilitates most cooperative interactions.

Keywords Play faces $\cdot$ Lip-smacking $\cdot$ Play fighting $\cdot$ Play units $\cdot$ Visual communication $\cdot$ Theropithecus gelada

Ivan Norscia and Elisabetta Palagi are the senior authors.

Communicated by K. Langergraber

Ivan Norscia

ivan.norscia@unito.it

Elisabetta Palagi

elisabetta.palagi@unipi.it

1 Department of Life Sciences and Systems Biology, University of Turin, Via Accademia Albertina 13, 10123 Torino, Italy
2 CNRS, EthoS (Éthologie animale et humaine), University of Rennes, Normandie University, UMR 6552, 35000 Rennes, France

3 Natural History Museum, University of Pisa, Via Roma 79, 56011 Calci, Pisa, Italy

4 Unit of Ethology, Department of Biology, University of Pisa, Via A. Volta 6, 56126 Pisa, Italy 


\section{Introduction}

Communication is the process during which senders produce specific designed displays to modify receivers' behaviours (Hebets and Papaj 2005). Due to its variability and unpredictability, social play is a good domain to test hypotheses on the evolution of signals that can have the immediate function of fine-tuning the session (Palagi et al. 2016). The most frequent type of social play is play fighting which includes motor actions often recruited from the agonistic context (Pellis et al. 2010a, b; Pellis and Burghardt 2017; Pellis and Pellis 2017; Nolfo et al. 2021). This type of play represents a challenge for animals that need to rapidly adopt flexible tactics and adjust their actions according to the intrinsic characteristics of the playmates (i.e. age, sex, kin) and the contexts under which the session is taking place (Pellegrini 2009). To be successful, play fighting requires sophisticated skills in performing actions and anticipating those of others (Fagen 1993; Spinka et al. 2001). This fine adjustment appears to be even more important when play fighting involves players of different ages, sexes, sizes and groups. A play fighting session involves actions that are borrowed from other functional contexts such as real aggression, submission and motherinfant behaviours. Playful patterns can therefore be defined as advantageous or disadvantageous as a function of the different domains in which they originate (Burghardt 2005; Pellis and Pellis 2009). To maintain a playful mood, individuals can alternate their advantageous/disadvantageous actions to make the session less ambiguous and well balanced (Gallo et al. 2021). In this respect, when a player gives the playmate the possibility to counterattack (e.g. role-reversal) or limits its strength by finely controlling motor actions (e.g. with self-handicapping behaviours); this actively contributes to make the session more balanced (symmetric) and prolonged (Pellis and Pellis 2009). However, role-reversal and selfhandicapping per se are not always effective to modulate the session and so signals may be needed for the session to be maintained (de Waal 2003; Palagi 2008; Pellis and Pellis 2009).

Play communication, which often relies on multiple sensory systems, can be either unimodal or multimodal (Winkler and Bryant 2021). Since play fighting requires a strong physical closeness between the players, visual signals acquire particular importance in this domain (Palagi 2008, 2009). Body postures, gestures and facial expressions often punctuate the play sessions in several animal species (Fagen 1981; Bekoff 2001; Palagi 2006; Palagi et al. 2016). Such visual signals can be specific to the play domain (context-dependent signals) or can convey different meanings depending on the species and context in which they are displayed (context-independent signals) (Maestripieri 1997; Palagi and Mancini 2011).
One of the typical context-dependent signals is the relaxed open mouth or play face (van Hooff and Preuschoft 2003; Davila-Ross and Dezecache 2021), a facial expression present in several primate and non-primate species (e.g. American black bear, Ursus americanus, Henry and Herrero 1974; domestic dogs, Canis lupus familiaris, Palagi et al. 2015; South American sea lions, Otaria flavescens, Llamazares-Martín et al. 2017a; ring-tailed lemurs, Lemur catta, Palagi et al. 2014; Norscia and Palagi 2016; Barbary macaques, Macaca sylvanus, Preuschoft 1992; lowland gorillas, Gorilla gorilla gorilla, Palagi et al. 2007; chimpanzees, Pan troglodytes, Palagi 2006; bonobos, Pan paniscus, Palagi 2008). The play face is used to express positive emotions and anticipate the affiliative nature of the behaviours that are going to be enacted (i.e. metacommunicative signal) (de Waal 2003; Pellis and Pellis 2009; Demuru et al. 2015).

Among the facial displays expressing positive intentions, lip-smacking is one of the most versatile in primates because it has been found in several contexts such as infant caring, subordination and affiliation, according to the different level of tolerance of a species (van Hooff 1962; Thierry 1984; Preuschoft 1992, 1995; Scopa and Palagi 2016). For example, in macaque species, lip-smacking, along with the silent-bared-teeth display, can be expressed in different contexts and conveys different meanings. In Japanese macaques, a highly despotic species, the silent-bared-teeth and lip-smacking are emitted by subordinates to signal their low-ranking status (de Waal and Luttrell 1985; Maestripieri 1996; Preuschoft 1995; Shimooka and Nakagawa 2014). In Tonkean macaques, a highly tolerant species, lip-smacking is present both during affiliative (Thierry 1984; Preuschoft 1995; Micheletta et al. 2013) and playful contacts (Pellis et al. 2011; Scopa and Palagi 2016) to convey a message of positive mood.

Whatever the kind of signal emitted, to make the exchange of information effective, both players need to be attentive to the face of the other so that they can correctly decode the signal and respond appropriately (Palagi and Mancini 2011). The receiver can reply with a simple playful pattern or by replicating the exact facial expression of the sender in a rapid $(<1 \mathrm{~s})$, unconscious way, a phenomenon known as rapid facial mimicry (RFM, Fig. 1a). The phenomenon of RFM has been demonstrated in several non-primate (Canis lupus familiaris, Palagi et al. 2015; Suricata suricatta, Palagi et al. 2019a; Helarctos malayanus, Taylor et al. 2019) and primate species (Theropithecus gelada, Mancini et al. 2013a; Pongo pygmaeus, Davila-Ross et al. 2008; Pan troglodytes and Gorilla gorilla gorilla, Palagi et al. 2019b). RFM can involve the perception-action mechanism and can have a role in emotion recognition (Palagi et al. 2020; Nieuwburg et al. 2021). By its potential role in favouring emotional sharing, RFM can have implications in determining the success of the play sessions. It has been demonstrated 


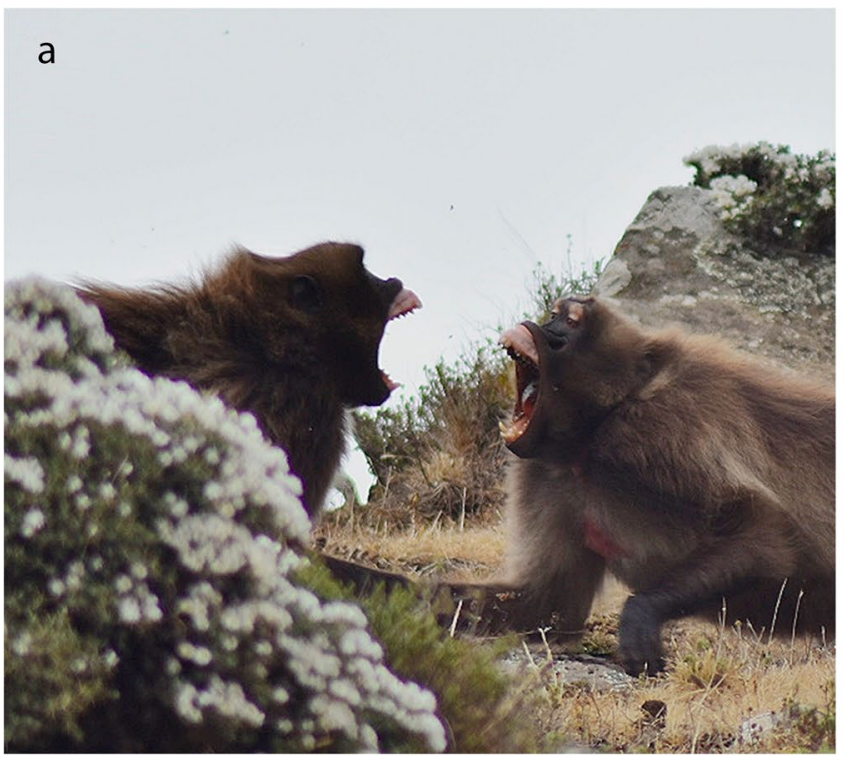

Fig. 1 a Picture showing two subadult playmates displaying rapid facial mimicry (RFM) of the play face (photo credits Alessandro Gallo). b Drawing showing the possible visual conditions during the expression of play faces. For the analyses, we considered a play face

that the occurrence of RFM during play encounters fosters motor synchronisation that translates into longer playful interactions (Mancini et al. 2013b; Palagi et al. 2015, 2019a; Scopa and Palagi 2016).

A good species to test hypotheses on playful communication is Theropithecus gelada. The gelada is a monkey species endemic to Ethiopia organised in a multilevel social system (Dunbar and Dunbar 1975) whose basic module is the one-male unit (OMU) composed of one leading male, several females and their offspring (Snyder-Mackler et al. 2012). Furthermore, inter-unit relationships are not based on social exchange and affiliation but on a high level of tolerance among different OMUs (Snyder-Mackler et al. 2012). The specific spatial aggregation maintained by the units underlines the extraordinary level of inter individual tolerance characterising geladas' complex fluid system (le Roux et al. 2011).

Since geladas mostly rely on grass for foraging, it has been supposed that their feeding ecology is at the basis of the high levels of tolerance between groups. The impossibility of monopolising such an abundant resource leads to low levels of food competition not only at inter- but also at intraunit level (le Roux et al. 2011). Within the OMU, geladas are characterised by relationships not strictly codified by rigid rank rules (Bergman 2010; Palagi and Bergman 2021) and, compared to other Cercopithecine species, group integrity is maintained by the strong affiliation among the individuals more than their dominance interactions (le Roux et al. 2011; Snyder-Mackler et al. 2012). b

no direct visual contact condition

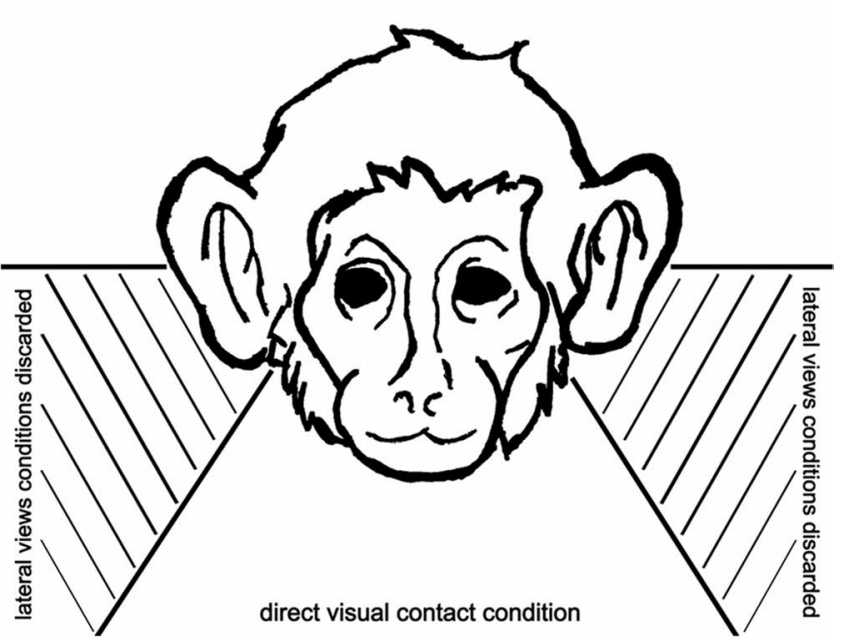

as perceived if subjects were in the 'direct visual contact condition', and as not perceived if subjects were in the 'no direct visual contact condition'. The doubtful cases falling in the 'lateral views conditions' were discarded from the analyses

Different OMUs spend most of their time in proximity thus favouring the formation of fluid groups of infants and juveniles belonging to both sexes (i.e. play units) that engage in high levels of playful contacts (wild, Dunbar and Dunbar 1975; Gallo et al. 2021; captive, Palagi and Mancini 2009, 2011). Hence, play is the only positive interaction linking subjects belonging to different OMUs (Dunbar and Dunbar 1975). Such playful encounters can vary in their competitive elements according to the level of familiarity of players (Gallo et al. 2021). Among primates, geladas possess one of the richest repertoires of facial expressions (Dunbar and Dunbar 1975; Leone et al. 2014; Lazow and Bergman 2020; Zanoli et al. 2021) that are performed in a highly flexible way under different contexts. As it occurs in Tonkean macaques, also geladas lip-smacking has a role in modulating affiliative interactions (e.g. reconciliation, Leone and Palagi 2010; consolation, Palagi et al. 2018) and can be performed during playful interactions (Palagi and Mancini 2011). Finally, geladas are the first monkey species in which the phenomenon of RFM has been demonstrated (Mancini et al. 2013a).

Here, we investigate how wild geladas adapt their playful communicative signals by testing the following predictions.

\section{Prediction 1: occurrence of play signals}

The asymmetry of a session can be measured by the play asymmetry index (PAI) that takes into account the number of advantageous, disadvantageous and neutral patterns each 
player engages in. The highest scores of PAI correspond to highly unbalanced session (see "Methods" for the mathematical formula). In wild geladas, play fighting is less symmetric and cooperative (more unbalanced) between subjects belonging to different OMUs and between individuals belonging to the same OMU (Gallo et al. 2021). The unbalanced nature of inter-OMU play translates into sessions characterised by a high degree of instability and short duration (Gallo et al. 2021). To avoid the risk of misunderstanding and escalation into real aggression, play fighting requires a clear use of signals (Aldis 1975; Palagi 2008, 2009). If play face (PF) and lip-smacking (LS) are signals that convey messages of positive intent (Maestripieri and Wallen 1997; de Waal 2003; Pellis and Pellis 2009), we expect to find these facial displays (PF, Prediction 1a; LS, Prediction 1b) to be more frequent during inter-OMU than during intra-OMU play sessions, as the former are characterised by the highest levels of asymmetry (see Gallo et al. 2021).

\section{Prediction 2: frequency and effects of RFM on the play sessions}

In geladas, RFM is present for context-dependent (e.g. play faces) but not for context-independent signals (e.g. lip-smacking) (Mancini et al. 2013a); hence, hereafter, we will refer to RFM in relation to play faces. This phenomenon improves the exchange of communicative signals between players thus leading to prolonged sessions (Mancini et al. 2013b). Little is known about the possible factors influencing RFM in geladas, although social bonding (e.g. kinship) seems to positively modulate and reinforce the phenomenon (Mancini et al. 2013a). If RFM is positively predicted by the level of familiarity shared by players, we predict facial mimicry to be more frequent when the session involves subjects of the same group (intra-OMU play) than when it involves subjects of different groups (inter-OMU play) (Prediction 2a). If RFM is predicted by playful synchronisation and mood sharing between subjects (Mancini et al. 2013b; Palagi et al. 2015, 2019a; Scopa and Palagi 2016), we expect the phenomenon to increase when the players engage in more balanced interactions characterised by low PAI values (Prediction 2b). Since the most balanced sessions are also the longest ones (Waller and Dunbar 2005; Davila-Ross et al. 2008, 2011; Gallo et al. 2021), if RFM has a role in balancing the session by fostering motor synchronisation, we predict a positive correlation between the number of RFM events and the duration of the session (Prediction $2 \mathrm{c}$ ).

\section{Methods}

\section{The species and data collection}

The study was conducted on a population of wild geladas living on the Kundi plateau (Wof-Washa area, Amhara region, Ethiopia, N9 ${ }^{\circ} 40.402^{\prime} \mathrm{E} 39^{\circ} 45.060^{\prime}$ ) from January to May 2019 (during both dry and early wet seasons). Two pairs of observers collected data by video recordings (Panasonic HC-V180 Full HD optic-zoom 50×, 2 s accuracy) and monitored two different parts of the plateau (Northern and Southern part, each part about $0.1 \mathrm{~km}^{2}$ ). For this study, we used data from 14 one-male units (OMUs) out of the 21 groups composing the total population of geladas living on the Kundi plateau (Caselli et al. 2021; Gallo et al. 2021).

The observers registered the OMUs identity and the number of subjects present in a range of 50 metres via instantaneous scan sampling (10-min intervals, Altmann 1974). After recognising the OMUs present in such a range, the observers video-recorded the activities between immature subjects (video length from 5 to $20 \mathrm{~min}$ ). While the first observer managed the camera, the second one described the ongoing activities (e.g. play activities, social interactions, proximity between players and their mothers), the identity of the subjects and their group membership. Therefore, the videos also included audio descriptions of the scenes and the subjects involved. When it was not immediately possible to determine the group membership of the players, the observers prolonged the registration until the OMUs split into single ones, thus permitting an a posteriori assignment of the players to their exact OMUs. We collected about 120 $\mathrm{h}$ of video, including $2 \mathrm{~h}$ of playful interactions $\left(N_{\text {session }}=\right.$ 527). It was not possible to record data blind because our study involved focal animals in the field.

\section{Video analysis and operational definitions}

By using the software VLC, we performed a video analysis on the 527 playful sessions recorded. To collect all the information required for an accurate analysis, we analysed each video-recorded playful session frame-by-frame (200-s accuracy). The video analysis was conducted by two observers and started after a training period conducted by EP and when the Cohen's Kappa between the observers was never below 0.75 .

A dyadic playful session started with an approach and a playful pattern directed by a subject towards a groupmate. The session ended when one of the two players moved away. Two sessions were considered different if divided by an interval of at least 10 s (Mancini and Palagi 2009; Gallo et al. 2021).

For each playful pattern of a given play session, we recorded the OMU membership of the players (intra-OMU vs inter-OMU), players' age- and sex-class following the criteria used in Dunbar and Dunbar (1975) and Gallo et al. (2021). We also recorded the duration (in seconds), the exact sequence of the patterns displayed, play faces (inter-observer reliability of the two observers, Cohen's Kappa 0.89), lip-smacking 
(Cohen's Kappa 0.84) and RFM events (Cohen's Kappa 0.96). When it was not possible to determine the sex of either player $\left(N_{\text {session }}=49\right)$, the sex-class was assigned randomly (as per Dunbar and Dunbar 1975). We included in the statistical analysis the dyadic playful interactions that were composed of at least three motor patterns and during which the players were always visible $\left(N_{\text {session }}=252\right)$. Since seasonality can affect the frequency of animal play (Barrett et al. 1992; Fagen 1993), following the season's classification included in Caselli et al. (2021), we divided our playful sessions according to the season in which they occurred (wet season: from January to March; dry season: from April to May).

Play Asymmetry Index (PAI) PAI was calculated based on advantageous (ADV), disadvantageous (DIS) and neutral play patterns (NEUTRAL) (Bauer and Smuts 2007; Ward et al. 2008; Cordoni et al. 2016; Llamazares-Martín et al. 2017b; Palagi et al. 2019a; Nolfo et al. 2021). A pattern was considered as ADV when a player directed an offensive pattern or when it was in a favourable position with respect to the playmate (e.g. an animal bites the other; an animal recovers a thing from the playmate). Therefore, the ADV category does not exclusively include offensive patterns. A pattern was scored as DIS when a player assumed a defensive or a selfhandicapping position (e.g. head rotation, play crouching). So, if a gelada engaged in an ADV pattern (e.g. biting) and the playmate counterattacked with another ADV pattern (e.g. biting), the outcome of the interaction would be balanced. The same occurs for the DIS patterns. All these patterns can occur outside or during a rough and tumble sequence. When it was not possible to clearly categorise ADV or DIS patterns within a rough and tumble interactions, the short sequence of rough and tumble was categorised as neutral. A neutral pattern is an action that does not provide any ADV or DIS to the player. See Table S1 for the categorisation of the playful patterns as advantageous, disadvantageous and neutral. The formula for the PAI calculation is the following:

\section{$(\mathrm{ADV} A+\mathrm{DIS} \mathrm{B})-(\mathrm{ADV} \mathrm{B}+\mathrm{DIS} \mathrm{A})$ \\ $($ ADV A + DIS B $)+($ ADV B + DIS A $)+$ NEUTRAL}

The PAI was calculated for each dyadic playful session. To measure the overall asymmetry of each session, we used the absolute PAI value (IPAII), which ranges from 0 (perfectly balanced session) to 1 (completely unbalanced session).

\section{Rapid facial mimicry (RFM)}

To examine the presence of RFM, defined as matching response produced by the receiver within $1 \mathrm{~s}$ after the perception of the triggering stimulus (Mancini et al. 2013a), we scored both play faces and full play faces as unique categories (PF) since they represent the two configurations of the relaxed open-mouth display (Palagi 2018). In this way, when we calculated the RFM, we did not consider the exact matching response (PF/PF; FPF/FPF) but, more generally, the congruent response (PF/PF; FPF/FPF; PF/FPF; FPF/PF) by following the previous results available for this species (Mancini et al. 2013a).

We focused on the face of one individual (the observer) to verify whether, within $1 \mathrm{~s}$, it varied as a function of the facial expression performed by the sender (hereafter, the trigger). The trigger was defined as the first playmate that emitted the stimulus (PF).

To reliably evaluate that the trigger's PF was actually the eliciting stimulus of the observer's PF, we considered only those events in which the observer, while looking at the trigger's face,

did not perform any PF in the second before the perception of the trigger's PF.

To evaluate the possibility for the observer to perceive the PF emitted by the trigger, we considered the observer's head orientation (Demuru et al. 2015; Scopa and Palagi 2016). We considered the PF as perceived when the trigger was in direct visual contact with the observer (i.e. within the range of its stereoscopic view). When the observer was facing away from the trigger (no direct visual contact), we considered the PF as not perceived. All the uncertain cases due to lateral views were discarded (see Fig. 1b). The Cohen's Kappa for direct and no-direct visual contacts was 0.88 .

Under the perception condition, the latency of the mimicry response was measured as follows: from the first frame corresponding to the first trigger's lip opening to the first frame corresponding to the first observer's lip opening.

\section{Statistics}

The statistical analyses were conducted in $\mathrm{R}$ (version 3.5.3, $\mathrm{R}$ Core Team 2019). To investigate if PFs were most frequently displayed during inter-OMU play (prediction 1a), we ran a linear mixed model $\left(\right.$ Model $\left._{1} ; N_{\text {observations }}=252\right)$ with the function lmer of the R-package 'lme4' (Bates et al. 2015). We verified the normal distribution and homogeneity of the residuals by looking at the qq-plot and plotting the residuals against the fitted values (Estienne et al. 2017). Due to the non-normal distribution of the residuals, the frequency of $\mathrm{PF}$ (outcome variable $=$ number of $\mathrm{PF} /$ play session duration) was transformed in a logarithmic scale. For this model, the fixed factors were as follows: OMU membership (Inter-OMU, Intra-OMU), sex of the players (same-sex, different-sex), age of the players (same-age, different-age), IPAIl, lip-smacking (presence, absence), season (wet, dry).

To investigate the distribution of LS in inter- and intra-OMU play sessions (Prediction 1b), we ran a generalised linear mixed model (Model ${ }_{2}$; R-package 'glmmTMB', Brooks et al. 2017) with LS frequency (number of LS/play session duration) as 
the outcome variable $\left(N_{\text {observations }}=252\right)$. Since the residuals were non-normally distributed, even when log-transformed, we chose a Beta distribution after fitting the model using the R-fitdist function (Delignette-Muller and Dutang 2015). For this model, the fixed factors were both used in the PF model, excluding the presence/absence of LS. To verify the occurrence of RFM events, we used a reduced dataset composed only of those sessions in which there were at least two play faces for both the players involved $\left(N_{\text {observations }}=116\right)$.

To evaluate whether OMU membership (Prediction 2a) and PAI values (Prediction $2 b$ ) influenced the frequency of RFM, we ran a third linear mixed model $\left(\right.$ Model $_{3}$; Bates et al. 2015) for which the outcome variable was the ratio between the total number of RFM events and the frequency of $\mathrm{PF}$ in the logarithmic scale (to reach a normal distribution of the residuals). We used the same fixed variables as the Model $_{1}$. In all the models, the playing dyad was entered as a random factor. We verified if the full models (including all the fixed factors) significantly differed from the null models (including only the random factor) by using a likelihood ratio test (ANOVA with argument 'Chisq'; Dobson 2002).

Finally, to test if the frequency of RFM predicted the duration of the play sessions $\left(N_{\text {observations }}=116\right)$ (prediction $2 \mathrm{c}$ ), we ran a fourth model (Model 4 : Bates et al. 2015). We built the model using the logarithm of the session's duration (sec) as the outcome variable (after checking the normal distribution of residuals with the same method used for the PF model). The fixed factors were Lip-smacking (presence, absence) and the total number of RFM events/frequency of PF. The influence on play duration of the OMU membership (inter-OMU, intra-OMU), sex of the players (same-sex, different-sex), age of the players (same-age, different-age), IPAIl and season (wet, dry) has already been tested in Gallo et al. (2021). For this reason, these variables were included in the LMM as control predictors. The playing dyad was considered as a random factor. To test the significance of the full model (Forstmeier and Schielzeth 2011), we compared it against a null model which comprised the control predictors and the random factor only, by using a likelihood ratio test (ANOVA with argument test 'Chisq'; Dobson 2002). For all four models, we checked variance inflation factors (VIF) using the 'car' package (Fox and Weisberg 2011) and we calculated the $p$-values of each predictor based on likelihood ratio tests between the full and the null models (R-function drop1, Barr et al. 2013).

\section{Results}

\section{Frequencies of play faces (PF) and lip-smacking (LS) in intra- and inter-OMU play (Model ${ }_{1} ;$ Model $_{2}$ )}

When investigating which variables predicted the frequency of playful facial expressions (PF model, $\mathrm{Model}_{1}$ ), we found that the full model significantly differed from the null model $\left(\chi^{2}=14.405, \mathrm{df}=6, p=0.025\right.$; Table 1$)$. No collinearity was found between the predictors $\left(\mathrm{VIF}_{\min }=1.007 ; \mathrm{VIF}_{\max }\right.$ $=1.106)$. The frequency of PFs was significantly predicted by OMU membership, with the playmates belonging to different OMUs performing the highest level of PFs (Table 1; Fig. 2) (prediction 1a supported). Focussing on the variables possibly affecting the frequency of lip-smacking (LS model, $M_{o d e l}$ ), we found that the full model did not significantly differ from the null model $\left(\chi^{2}=1.915, \mathrm{df}=8, p=0.860\right)$ (prediction $1 \mathrm{~b}$ not supported).

\section{Role of familiarity and play asymmetry on the frequency of RFM (Model ${ }_{3}$ )}

The full model built to evaluate which variables predicted the distribution of RFM significantly differed from the null model $\left(\chi^{2}=25.750, \mathrm{df}=6, p<0.001\right.$; Table 2$)$. No collinearity was found between the fixed factors $\left(\mathrm{VIF}_{\min }=1.009\right.$; $\left.\mathrm{VIF}_{\max }=1.108\right)$. The frequency of RFM was positively predicted by the low levels of IPAIl (Fig. 3a; Table 2; prediction $2 \mathrm{~b}$ supported). Moreover, the presence of LS was associated with the highest frequency of RFM (Fig. 3b). The level of familiarity (OMU membership) did not influence the distribution of RFM during the playful session (Prediction 2a not supported).

\section{Effect of RFM and LS on play duration (Model ${ }_{4}$ )}

Finally, when testing if the frequency of RFM and the presence of LS predicted the duration of the session, the full model significantly differed from the null model $\left(\chi^{2}=91.076, \mathrm{df}=\right.$ $2, p<0.001$; Table 3$)$. No collinearity was found between the

Table 1 Results of the LMMs showing the effects of the fixed factors on play face frequency

\begin{tabular}{|c|c|c|c|c|c|}
\hline Fixed factors & Estimate & SE & $\mathrm{df}$ & $z$ & $p$ \\
\hline Intercept & -0.304 & 0.088 & $\mathrm{a}$ & -3.473 & $\mathrm{a}$ \\
\hline Sex (mismatched) $)^{\mathrm{b}, \mathrm{c}}$ & -0.017 & 0.050 & 252 & -0.344 & 0.731 \\
\hline Age (mismatched $)^{\mathrm{b}, \mathrm{c}}$ & -0.026 & 0.043 & 252 & -0.599 & 0.550 \\
\hline OMU (intra) $)^{\mathrm{b}, \mathrm{c}}$ & -0.122 & 0.043 & 252 & -2.836 & 0.005 \\
\hline absPAI & 0.073 & 0.075 & 252 & 0.970 & 0.333 \\
\hline Lipsmack (presence) ${ }^{\mathrm{b}, \mathrm{c}}$ & -0.083 & 0.071 & 252 & -1.172 & 0.242 \\
\hline Season (wet) $)^{b, c}$ & -0.142 & 0.078 & 252 & -1.812 & 0.071 \\
\hline
\end{tabular}

${ }^{a}$ Not shown as not having a meaningful interpretation

${ }^{b}$ Estimate \pm SE refer to the difference of the response between the reported level of this categorical predictor and the reference category of the same predictor

'These predictors were dummy-coded, with the 'Sex (matched)', 'Age (matched)', 'OMU (inter)', 'Lipsmack (absence)', 'Season (dry)' being the reference categories

Full vs control model $\chi^{2}=14.405, \mathrm{df}=6, p=0.025$; The significant $\mathrm{P}$ values are in bold 


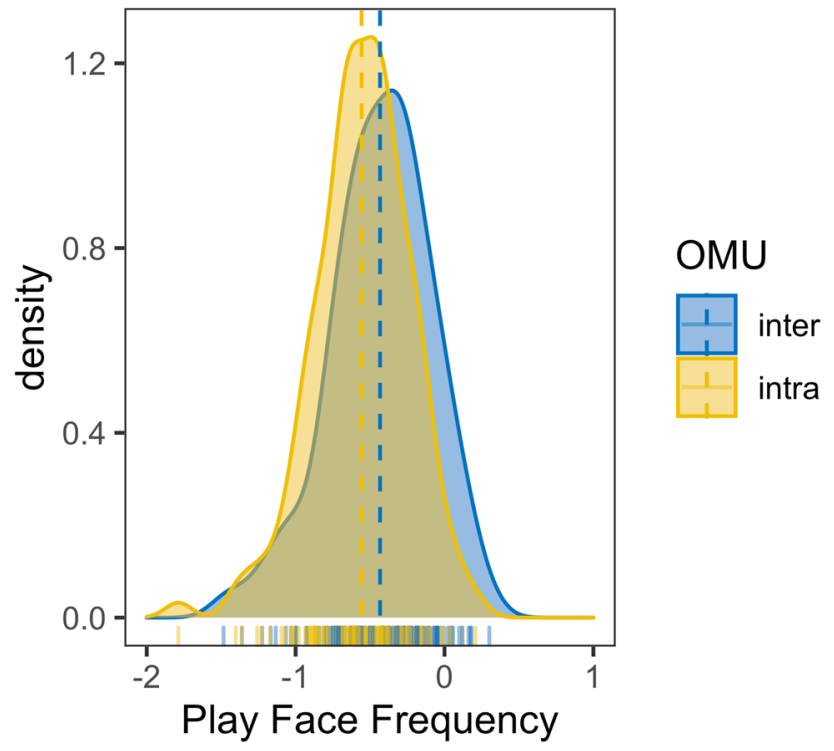

Fig. 2 Density plot, drawn with the R-package 'ggpubr' (Kassambara 2020), showing the frequency of play faces in the inter-OMU (blue density curve) and in the intra-OMU (yellow density curve) conditions. Individual observations are presented under the density curves with pipe symbols. Dotted lines represent the mean values for each condition

predictors $\left(\mathrm{VIF}_{\min }=1.024 ; \mathrm{VIF}_{\max }=1.124\right)$. The frequency of RFM (Fig. 4a) was positively associated with the duration of the playful sessions (prediction 2c supported). Moreover, the longest sessions were characterised by the presence of LS (Fig. 4b).

Table 2 Results of the LMMs showing the effects of the fixed factors on RFM frequency

\begin{tabular}{|c|c|c|c|c|c|}
\hline Fixed factors & Estimate & SE & df & $z$ & $p$ \\
\hline Intercept & 0.643 & 0.105 & $\mathrm{a}$ & 6.098 & $\mathrm{a}$ \\
\hline Sex (mismatched) $)^{\mathrm{b}, \mathrm{c}}$ & -0.013 & 0.072 & 116 & -0.183 & 0.855 \\
\hline Age (mismatched) $)^{\mathrm{b}, \mathrm{c}}$ & -0.003 & 0.060 & 116 & -0.049 & 0.961 \\
\hline $\mathrm{OMU}(\text { intra })^{\mathrm{b}, \mathrm{c}}$ & 0.098 & 0.059 & 116 & 1.664 & 0.099 \\
\hline absPAI & -0.405 & 0.111 & 116 & -3.661 & $\mathbf{0 . 0 0 0}$ \\
\hline $\begin{array}{l}\text { Lipsmack } \\
\quad \text { (Presence) }^{\mathrm{b}, \mathrm{c}}\end{array}$ & 0.208 & 0.083 & 116 & 2.510 & 0.013 \\
\hline Season $(\text { Wet })^{b, c}$ & 0.156 & 0.096 & 116 & 1.638 & 0.104 \\
\hline
\end{tabular}

${ }^{a}$ Not shown as not having a meaningful interpretation

${ }^{b}$ Estimate \pm SE refer to the difference of the response between the reported level of this categorical predictor and the reference category of the same predictor

'These predictors were dummy-coded, with the 'Sex (matched)', 'Age (matched)', 'OMU (inter)', 'Lipsmack (absence)', 'Season (dry)' being the reference categories

Full vs control model $\chi^{2}=25.750, \mathrm{df}=6, p=0.00025$; The significant $\mathrm{P}$ values are in bold

\section{Discussion}

Here, we focused on the role of visual communication signals in the playful domain in a wild monkey species, the gelada. Our findings show that context-dependent facial expressions (play faces) have a role in the management of playful interactions (prediction 1a supported). In wild geladas, contrary to lip-smacking (predicting affiliation in tolerant species, Thierry 1984, 1985, 1986; Preuschoft 1992, 1995; Matsumura 1994, 1997; Maestripieri and Wallen 1997; Palagi and Mancini 2011), the use of play faces depended on playmates' group membership (Table 1). The incidence of RFM (Fig. 1a), a phenomenon demonstrated only for the play faces in this species (Mancini et al. 2013a), was predicted by the playful tactics (i.e. most cooperative play) (Table 2; Fig. $3 b$; prediction $2 b$ supported) and the occurrence of lip-smacking (Table 2; Fig. 3a).

Gallo et al. (2021) demonstrated that inter-OMU play fighting is more competitive (i.e. most asymmetric play sessions) than intra-OMU play fighting. In the present study, play faces were particularly frequent when the players did not belong to the same OMU (Fig. 2) thus suggesting that unfamiliar subjects, when facing such competitive interactions, need signal redundancy to communicate the playful nature of their agonistic patterns (Prediction 1a supported). Our findings on wild geladas are in line with data coming from captive populations. Palagi and Mancini (2011) found that when the session involved agemismatched dyads (e.g. adult-infant), the adult subjects engaged in the highest rates of play faces. Similar evidence also comes from primate species showing high levels of despotism such as ring-tailed lemurs (Pereira and Kappeler 1997). In this species, the use of play faces is redundant when play fighting becomes highly unbalanced independently from the age-matching of the players (Palagi et al. 2014). Signal redundancy is also present in chimpanzees that can strategically modulate their play faces during high-risk situations. When playing with infants, adolescent chimpanzees can enhance the use of play faces when they are observed by the mothers of their playmates to possibly adjust their facial displays depending on a specific audience when the play became rough (Flack et al. 2004). An additional example on the importance of play faces during sessions involving a certain degree of risk comes from bonobos (Palagi 2006). Under space reduction conditions, captive bonobos engage in a high number of play faces (Tacconi and Palagi 2009). Playing in limited spaces (i.e. indoor areas), where the escape opportunities are reduced, implies a higher level of social tension that affects the outcome of the session. The presence of clear signals conveying a positive intent is necessary to downgrade the arousal 


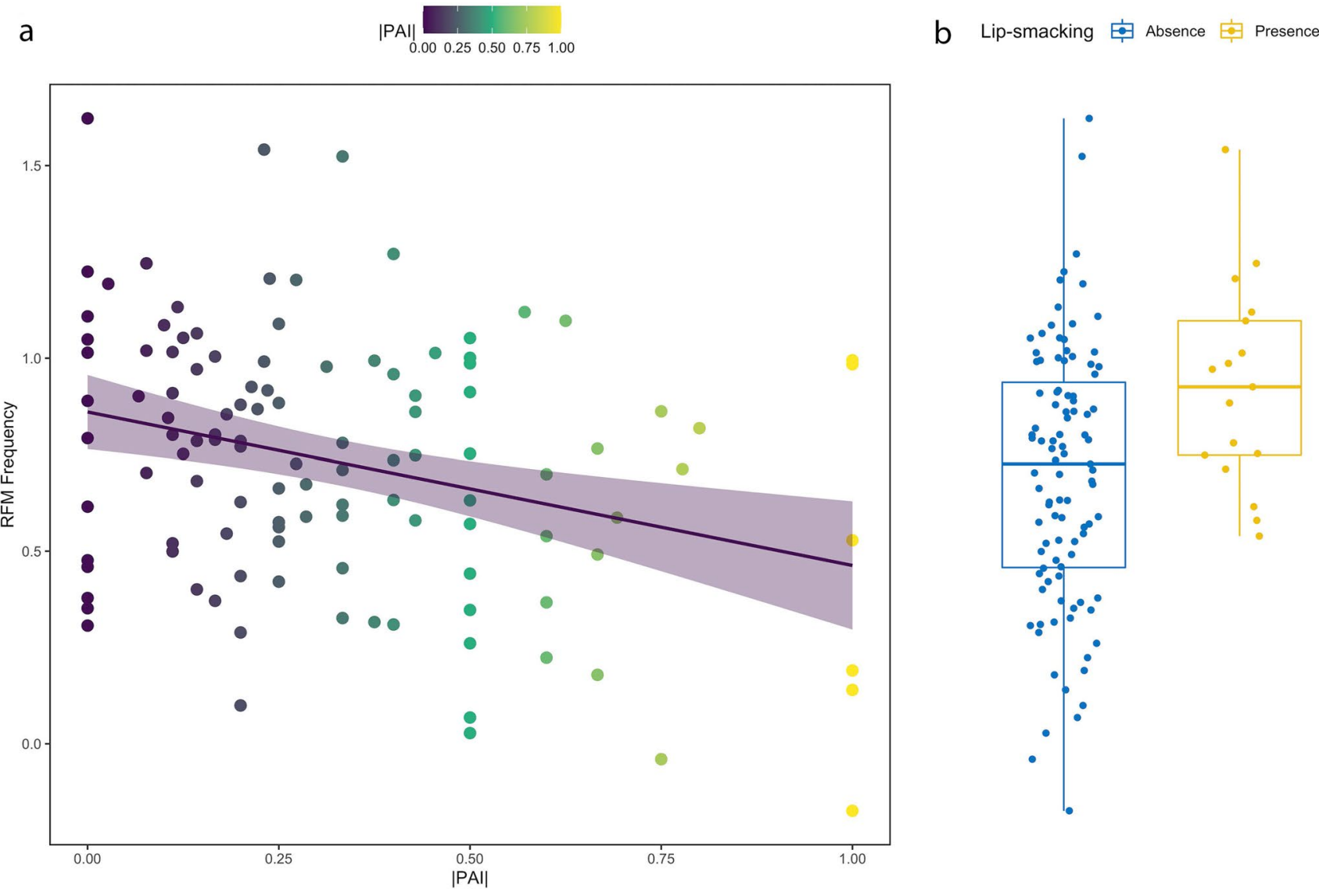

Fig. 3 a Scatter plot showing the relationship between the frequency of RFM and the play asymmetry index absolute value (IPAIl). Dots' colour follows the variation of IPAII values. The purple line represents the linear regression between the variables and the respective confidence interval. b Box plot showing the RFM frequency varia-

Table 3 Results of the LMMs showing the effects of the fixed factors on the duration of the session

\begin{tabular}{|c|c|c|c|c|c|}
\hline Fixed factors & Estimate & SE & df & $z$ & $p$ \\
\hline Intercept & 0.926 & 0.077 & $\mathrm{a}$ & 12.036 & $\mathrm{a}$ \\
\hline Sex (mismatched $)^{\mathrm{b}, \mathrm{c}}$ & 0.103 & 0.052 & 109.683 & 1.998 & 0.048 \\
\hline Age (mismatched) ${ }^{\mathrm{b}, \mathrm{c}}$ & 0.009 & 0.043 & 110.139 & 0.208 & 0.835 \\
\hline OMU (intra) $)^{\mathrm{b}, \mathrm{c}}$ & 0.102 & 0.043 & 108.186 & 2.395 & 0.018 \\
\hline absPAI & -0.238 & 0.078 & 107.787 & -3.032 & 0.003 \\
\hline Lipsmack (presence) $)^{\mathrm{b}, \mathrm{c}}$ & 0.123 & 0.058 & 90.398 & 2.140 & 0.035 \\
\hline Season (wet) ${ }^{b, c}$ & 0.050 & 0.068 & 112.682 & 0.734 & 0.464 \\
\hline RFM frequency & 0.036 & 0.003 & 105.289 & 10.998 & 0.000 \\
\hline
\end{tabular}

${ }^{a}$ Not shown as not having a meaningful interpretation

${ }^{b}$ Estimate \pm SE refer to the difference of the response between the reported level of this categorical predictor and the reference category of the same predictor

'These predictors were dummy-coded, with the 'Sex (matched)', 'Age (matched)', 'OMU (inter)', 'Lipsmack (absence)', 'Season (dry)' being the reference categories

Full vs control model $\chi 2=91.076, \mathrm{df}=2, p<0.001$; The significant $\mathrm{P}$ values are in bold tion in absence (blue box) and in presence (yellow box) of lip-smacking. (Plots were created in R using the 'ggplot2' package; Wickham 2016). Boxes indicate the inter-quartile range (IQR), with the central line depicting the median and the whiskers extending to $1.5 * \mathrm{IQR}$

possibly induced by crowding conditions and/or the presence of an audience (van Hooff 1989; Judge and de Waal 1993; Flack et al. 2004; Cordoni and Palagi 2007; Palagi et al. 2007). Considering the enlarged group association of wild geladas made up of familiar and less familiar subjects, it is difficult to understand if the redundant use of play faces during inter-OMU play is due to the presence of adults of other OMUs or is simply linked to the necessity to manage particularly asymmetric and risky sessions.

Given that the performance of lip-smacking, a contextindependent signal (Palagi and Mancini 2011), was not predicted by the group membership of the players involved, we can hypothesis that during the play, the context-specific signals (i.e. the play face) are more sensitive to the variability of each play session both in terms of player familiarity and play modality (Palagi and Mancini 2011; Gallo et al. 2021) (Prediction 1b not supported).

Although lip-smacking did not seem to be sensitive to either the familiarity shared by the players or their play modality, it has an important role in enhancing the RFM 


\section{a}

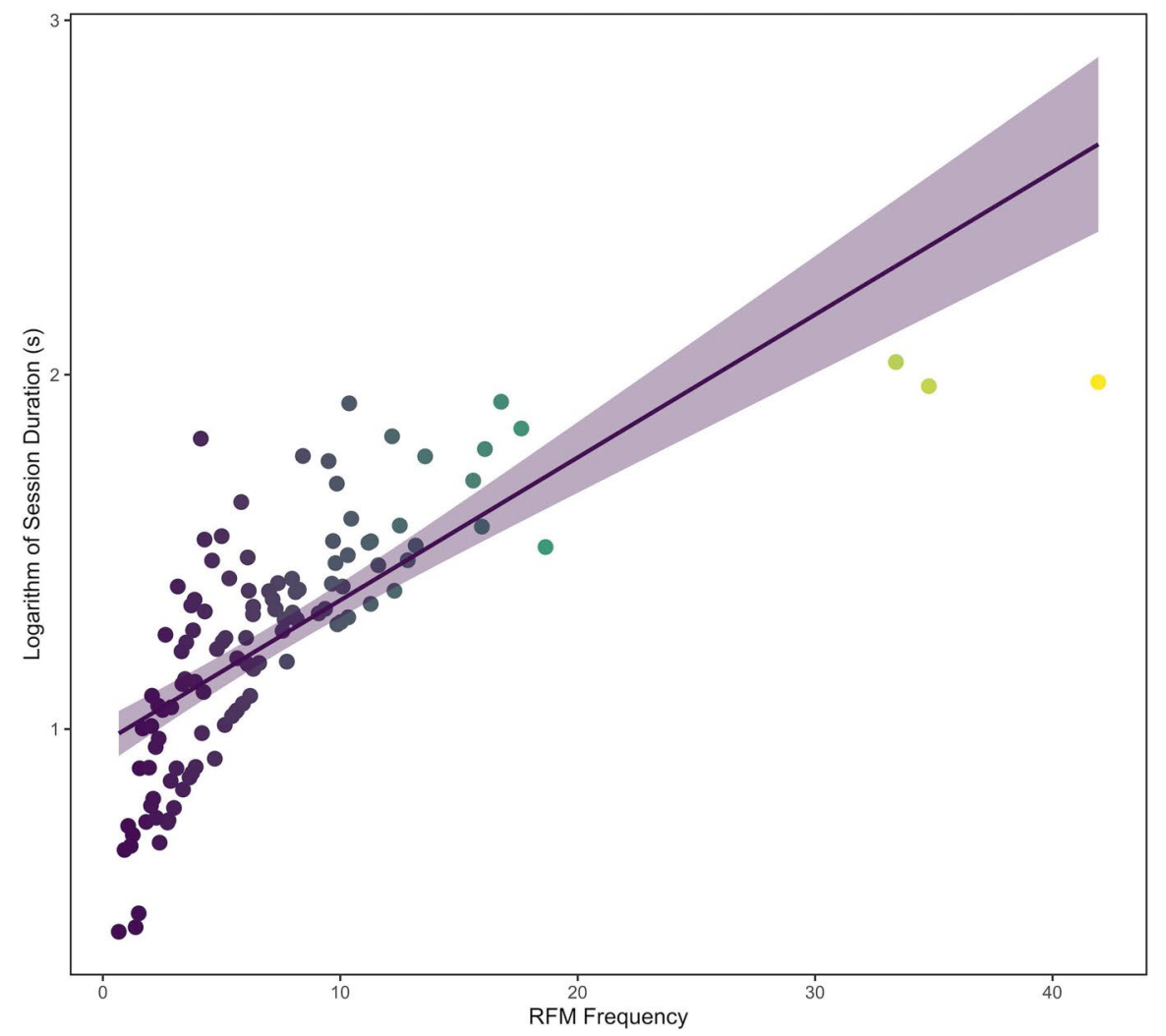

b Lip-smacking
Fig. 4 a Scatter plot showing the relationship between the logarithm of the play session duration and the frequency of RFM. Dots' colour follows the variation of RFM frequency. The purple line represents the linear regression between the variables and the respective confidence interval. b Box plot showing the variation of the play ses-

phenomenon. Indeed, we found that when players displayed lip-smacking, the play faces were mimicked more frequently (Fig. 3a). In this view, by expressing affiliative motivation, lip-smacking seems to have an indirect role in enhancing play communication. It is worth noting that the incidence of RFM was obtained by normalising the RFM events on the number of play faces performed in each session. Such analytical approach makes the calculation of RFM incidence independent from the number of play faces displayed by the players. This allows a precise evaluation of the entity of the phenomenon that can be investigated without any bias due to the length of the playful interaction and, consequently, to the total number of playful facial expressions performed.

We did not find any evidence of a role of group membership in shaping the mimicry phenomenon. RFM appears to be strictly associated to the cooperative modality of the session more than to players' familiarity: the more symmetric the session, the higher the incidence of RFM (Fig. 3b) (prediction 2a not supported). There is evidence that RFM can help synchronise motor actions between players both in sion duration in absence (blue box) and in presence (yellow box) of lip-smacking (Plots were created in R using the 'ggplot2' package; Wickham 2016). Boxes indicate the inter-quartile range (IQR), with the central line depicting the median and the whiskers extending to $1.5 * \mathrm{IQR}$

human and non-human animals (Palagi et al. 2020; Nieuwburg et al. 2021). The linkage between RFM and play equilibrium is particularly evident in tolerant (e.g. Macaca tonkeana, Scopa and Palagi 2016) and cooperative species (e.g. Suricata suricatta, Palagi et al. 2019a) whose relationships, not relying on formalised hierarchical behaviours, need flexible communicative modules to manage and negotiate fluid social interactions, including play (Freeberg et al. 2012; Kavanagh et al. 2021).

Our results also show the effects of communicative signals on the length of playful interactions. We found that the duration of each session was positively predicted by both the presence of lip-smacking (Table 3; Fig. 4b) and the incidence of RFM (Fig. 4a) (prediction 2c supported). The recruitment of lip-smacking from other affiliative contexts seems to reinforce the playful mood, enhance the cooperation among players (Scopa and Palagi 2016) and, consequently, increase play duration. During an RFM interaction, the subjects must be attentive to the playmate's face, perceive the facial expression and correctly decode the information that 
such expression conveys (Provine 1996, 2004; Palagi 2018). In this perspective, the presence of RFM phenomenon can improve the communication among players and promote the behavioural coordination that leads to prolonged interactions (Pellis and Pellis 2009; Palagi and Mancini 2011). Our finding is in line with the previous evidence on captive geladas (Mancini et al. 2013b) and Tonkean macaques (Scopa and Palagi 2016) demonstrating that RFM is a tool to increase the duration of play sessions. Prolonging playful interactions maximises the benefits of this activity by allowing the players to improve their motor and social competence under a safe behavioural context (Bekoff and Byers 1981; Pellegrini and Smith 1998; Pellis and Iwaniuk 2000; Nunes et al. 2004; Bekoff and Pierce 2009; Pellis et al. 2010a, b; Nolfo et al. 2021).

In conclusion, the importance of RFM in modulating play fighting is unveiled in geladas considering their peculiar social organisation (Snyder-Mackler et al. 2012). Play fighting is the only positive direct social interaction that can involve subjects of different OMUs (Dunbar and Dunbar 1975). Therefore, a sophisticated communication system such as RFM can create a 'safe environment' for the players of both the same and different OMUs. We should also consider that immature play fighting occurs in a strict proximity of adults of different OMUs (audience). In this perspective, further exploration on the audience effect on the incidence of both play faces and RFM would be necessary to verify if such an exchange of signals strategically conveys information to third parties or is simply the byproduct of the emotional arousal experienced by wild geladas during play.

Supplementary Information The online version contains supplementary material available at https://doi.org/10.1007/s00265-022-03126-4.

Acknowledgements A special thanks to the European Endangered Species Programme coordinator, Achim Johann, for helping in the fundraising. We acknowledge the Ethiopian Wildlife Conservation Authority (EWCA) for granting us permission to conduct this research. Moreover, we thank Daniel Sebhatu, Elijah Nevers, Elias Kahsay for their support in the field and Carlo Dagradi for his help in the data collection. We wish to thank the two anonymous reviewers for their helpful suggestions that allowed improving this work.

Funding Funding for this research was provided by the zoos of the European Association of Zoo and Aquaria (EAZA) via Natural History Museum of the University of Pisa ( $\mathrm{N}^{\circ}$ Protocol 0000384/2018): the Animal Research Conservation in Action Onlus of Parco Natura Viva (Bussolengo, Italy), the Bronx Zoo (Bronx, United State of America), the Colchester Zoo (Colchester, Great Britain), the Diergaarde Blijdorp Rotterdam zoo (Rotterdam, Netherlands), the Dudley Zoological Gardens (Dudley, Great Britain), the Espace Zoologique de La Boissière-du-Doré (La Boissière, France), the Giardino Zoologico di Pistoia (Pistoia, Italy), the Jardin Zoologique de la Citadelle de Besançon (Besançon, France), the NatureZoo Rheine (Rheine, Germany), the Parc des Félins (Lumigny-Nesles-Ormeaux, France), the Parco Natura Viva (Bussolengo, Italy), the Parco Zoo Falconara (Falconara, Italy), the Wilhelma Zoologisch-Botanischer Garten Stuttgart (Stuttgart, Germany), the Zoo Veszprém (Veszprém, Hungary), the Zoo Zürich (Zürich, Switzerland) and the Associazione Italiana Guardiani di Zoo (AIGZoo). Additional funding: University of Torino (DBIOS9 provided the $\mathrm{PhD}$ grant of $\mathrm{MC}$ via the Italian Ministry of Education, University and Research (MIUR), the PhD grant of AZ from Compagnia di San Paolo. AG was funded by the University of Torino (DBIOS) via the Italian Ministry of Education Youth Fund.

Data availability The dataset used for the analyses is provided as supplementary material.

\section{Declarations}

Ethics approval This study was approved by University of Pisa (Animal Care and Use Board) (Italy), the University of Turin (Italy) and the Ethiopian Wildlife Conservation Authority (EWCA). Since the study was purely observational, the committee waived the need for a permit. The study was conducted with no manipulation of animals. All applicable international, national and/or institutional guidelines for the use of animals were followed.

Conflict of interest The authors declare no competing interests.

Open Access This article is licensed under a Creative Commons Attribution 4.0 International License, which permits use, sharing, adaptation, distribution and reproduction in any medium or format, as long as you give appropriate credit to the original author(s) and the source, provide a link to the Creative Commons licence, and indicate if changes were made. The images or other third party material in this article are included in the article's Creative Commons licence, unless indicated otherwise in a credit line to the material. If material is not included in the article's Creative Commons licence and your intended use is not permitted by statutory regulation or exceeds the permitted use, you will need to obtain permission directly from the copyright holder. To view a copy of this licence, visit http://creativecommons.org/licenses/by/4.0/.

\section{References}

Aldis O (1975) Play fighting. Academic Press, New York

Altmann J (1974) Observational study of behavior: sampling methods. Behaviour 49:227-266

Barr DJ, Levy R, Scheepers C, Tily HJ (2013) Random effects structure for confirmatory hypothesis testing: keep it maximal. J Mem Lang 68:255-278. https://doi.org/10.1016/j.jml.2012.11.001

Barrett L, Dunbar RI, Dunbar P (1992) Environmental influences on play behaviour in immature gelada baboons. Anim Behav 44:111-115. https://doi.org/10.1016/S0003-3472(05)80760-2

Bates D, Mächler M, Bolker B, Walker S (2015) Fitting linear mixedeffects models using lme4. J Stat Softw 67:1-48

Bauer EB, Smuts BB (2007) Cooperation and competition during dyadic play in domestic dogs, Canis familiaris. Anim Behav 73:489-499. https://doi.org/10.1016/j.anbehav.2006.09.006

Bekoff M (2001) Social play behaviour. Cooperation, fairness, trust, and the evolution of morality. J Conscious Stud 8:81-90

Bekoff M, Byers JA (1981) A critical reanalysis of the ontogeny and phylogeny of mammalian social and locomotor play: an ethological hornet's nest. In: Immelmann K, Barlow G, Petrinovich L, Martin M (eds) Behavioral development. Cambridge University Press, London, pp 296-337 
Bekoff M, Pierce J (2009) Wild justice: the moral lives of animals. University of Chicago Press, Chicago

Bergman TJ (2010) Experimental evidence for limited vocal recognition in a wild primate: implications for the social complexity hypothesis. Proc R Soc Lond B 277:3045-3053. https://doi.org/ 10.1098/rspb.2010.0580

Brooks ME, Kristensen K, van Benthem KJ, Magnusson A, Berg CW, Nielsen A, Skaug HJ, Machler M, Bolker BM, Bolker BM (2017) glmmTMB balances speed and flexibility among packages for zero-inflated generalised linear mixed modeling. R J 9:378-400. https://doi.org/10.3929/ethz-b-000240890

Burghardt GM (2005) The genesis of animal play: testing the limits. MIT Press, Cambridge

Caselli M, Zanoli A, Dagradi C et al (2021) Wild geladas (Theropithecus gelada) in crops-more than in pasture areas-reduce aggression and affiliation. Primates 62:571-584. https://doi. org/10.1007/s10329-021-00916-8

Cordoni G, Palagi E (2007) Response of captive lowland gorillas (Gorilla gorilla gorilla) to different housing conditions: testing the aggression-density and coping models. J Comp Psychol 121:171. https://doi.org/10.1037/0735-7036.121.2.171

Cordoni G, Nicotra V, Palagi E (2016) Unveiling the 'secret' of dog play success: asymmetry and signals. J Comp Psychol 130:278-287. https://doi.org/10.1037/com0000035

Davila-Ross M, Dezecache G (2021) The complexity and phylogenetic continuity of laughter and smiles in hominids. Front Psychol 3(12):648497. https://doi.org/10.3389/fpsyg.2021.648497

Davila-Ross M, Menzler S, Zimmermann E (2008) Rapid facial mimicry in orangutan play. Biol Lett 4:27-30. https://doi.org/10. 1098/rsbl.2007.0535

Davila-Ross M, Allcock B, Thomas C, Bard KA (2011) Aping expressions? Chimpanzees produce distinct laugh types when responding to laughter of others. Emotion 11:1013-1020. https://doi.org/10.1037/a0022594

de Waal FBM (2003) Darwin's legacy and the study of primate visual communication. Ann N Y Acad Sci 1000:7-31. https://doi.org/ 10.1196/annals. 1280.003

de Waal FBM, Luttrell LM (1985) The formal hierarchy of rhesus macaques: an investigation of the bared-teeth display. Am J Primatol 9:73-85. https://doi.org/10.1002/ajp.1350090202

Delignette-Muller ML, Dutang C (2015) fitdistrplus: An R package for fitting distributions. J Stat Softw 64:1-34

Demuru E, Ferrari PF, Palagi E (2015) Emotionality and intentionality in bonobo playful communication. Anim Cogn 18:333-344. https://doi.org/10.1007/s10071-014-0804-6

Dobson AJ (2002) An introduction to generalized linear models. Chapman and Hall, Boca Raton

Dunbar RIM, Dunbar EP (1975) Social dynamics of gelada baboons. Contrib Primatol 6:1-157

Estienne V, Mundry R, Kühl HS, Boesch C (2017) Exploitation of underground bee nests by three sympatric consumers in Loango National Park, Gabon. Biotropica 49:101-109. https:// doi.org/10.1111/btp.12354

Fagen R (1981) Animal play behavior. Oxford University, New York

Fagen R (1993) Primate juveniles and primate play. In: Pereira ME, Fair-banks LA (eds) Juvenile primates. Oxford University Press, New York, pp 182-196 367-415

Flack JC, Jeannotte LA, de Waal FBM (2004) Play signaling and the perception of social rules by juvenile chimpanzees (Pan troglodytes). J Comp Psychol 118:149-159. https://doi.org/10. 1037/0735-7036.118.2.149

Forstmeier W, Schielzeth H (2011) Cryptic multiple hypotheses testing in linear models: overestimated effect sizes and the winner's curse. Behav Ecol Sociobiol 65:47-55. https://doi.org/ 10.1007/s00265-010-1038-5
Fox J, Weisberg S (2011) Multivariate linear models in R. Sage Publications, Thousand Oaks

Freeberg TM, Dunbar RI, Ord TJ (2012) Social complexity as a proximate and ultimate factor in communicative complexity. Philos Trans R Soc B 367:1785-1801. https://doi.org/10.1098/ rstb.2011.0213

Gallo A, Caselli M, Norscia I, Palagi E (2021) Let's unite in play! Play modality and group membership in wild geladas. Behav Process 184:104338. https://doi.org/10.1016/j.beproc.2021.104338

Hebets EA, Papaj DR (2005) Complex signal function: developing a framework of testable hypotheses. Behav Ecol Sociobiol 57:197214. https://doi.org/10.1007/s00265-004-0865-7

Henry JD, Herrero SM (1974) Social play in the American black bear: its similarity to canid social play and an examination of its identifying characteristics. Am Zool 14:371-389. https://doi.org/10. 1093/icb/14.1.371

Judge PG, de Waal FBM (1993) Conflict avoidance among rhesus monkeys: coping with short-term crowding. Anim Behav 46:221232. https://doi.org/10.1006/anbe.1993.1184

Kassambara A (2020) Ggpubr: 'ggplot2' based publication ready plots. https://cran.R-project.org/package $=$ ggpubr

Kavanagh E, Street SE, Angwela et al (2021) Dominance style is a key predictor of vocal use and evolution across nonhuman primates. R Soc Open Sci 8:210873. https://doi.org/10.1098/rsos.210873

Lazow SP, Bergman TJ (2020) The structural and motivational role of the unique lip-flip movement in the gelada (Theropithecus gelada) facial display repertoire. Am J Phys Anthropol 172:280 290. https://doi.org/10.1002/ajpa.24031

Le Roux A, Beehner JC, Bergman TJ (2011) Female philopatry and dominance patterns in wild geladas. Am J Primatol 73:422-430. https://doi.org/10.1002/ajp.20916

Leone A, Palagi E (2010) Reconciling conflicts in a one-male society: the case of geladas (Theropithecus gelada). Primates 51:203212. https://doi.org/10.1007/s10329-010-0188-4

Leone A, Ferrari PF, Palagi E (2014) Different yawns, different functions? Testing social hypotheses on spontaneous yawning in Theropithecus gelada. Sci Rep 4:4010. https://doi.org/10.1038/ srep04010

Llamazares-Martín C, Scopa C, Guillén-Salazar F, Palagi E (2017a) Relaxed open mouth reciprocity favours playful contacts in South American sea lions (Otaria flavescens). Behav Process 140:8795. https://doi.org/10.1016/j.beproc.2017.04.007

Llamazares-Martín C, Scopa C, Guillén-Salazar F, Palagi E (2017b) Strong competition does not always predict play asymmetry: the case of South American sea lions (Otaria flavescens). Ethology 123:270-282. https://doi.org/10.1111/eth.12594

Maestripieri D (1996) Gestural communication and its cognitive implications in pigtail macaques (Macaca nemestrina). Behaviour 133:997-1022

Maestripieri D (1997) Gestural communication in macaques: usage and meaning of nonvocal signals. Evol Commun 1:193-222

Maestripieri D, Wallen K (1997) Affiliative and submissive communication in rhesus macaques. Primates 38:127-138

Mancini G, Ferrari PF, Palagi E (2013a) Rapid facial mimicry in geladas. Sci Rep 3:1527. https://doi.org/10.1038/srep01527

Mancini G, Ferrari PF, Palagi E (2013b) In play we trust. Rapid facial mimicry predicts the duration of playful interactions in geladas. PLoS One 8:e66481. https://doi.org/10.1371/journal.pone.00664 81

Matsumura S (1994) Affiliative mounting interference in Macaca maurus. Kyoto University Overseas Research Report of Studies on Asian Non-Human Primates (No. 9). Kyoto University Primate Research Institute, Kyoto

Matsumura S (1997) Mothers in a wild group of moor macaques (Macaca maurus) are more attractive to other group members 
when holding their infants. Folia Primatol 68:77-85. https://doi. org/10.1159/000157234

Micheletta J, Engelhardt A, Matthews L, Agil M, Waller BM (2013) Multicomponent and multimodal lipsmacking in crested macaques (Macaca nigra). Am J Primatol 75:763-773. https:// doi.org/10.1002/ajp.22105

Nieuwburg EG, Ploeger A, Kret ME (2021) Emotion recognition in nonhuman primates: how experimental research can contribute to a better understanding of underlying mechanisms. Neurosci Biobehav Rev 123:24-47. https://doi.org/10.1016/j.neubiorev. 2020.11.029

Nolfo AP, Casetta G, Palagi E (2021) Play fighting in wild spotted hyaenas: like a bridge over the troubled water of a hierarchical society. Anim Behav 180:363-373. https://doi.org/10.1016/j. anbehav.2021.07.012

Norscia I, Palagi E (2016) The missing lemur link: an ancestral step in the evolution of human behaviour. Cambridge University Press, Cambridge

Nunes S, Muecke EM, Sanchez Z, Hoffmeier RR, Lancaster LT (2004) Play behavior and motor development in juvenile Belding's ground squirrels (Spermophilus beldingi). Behav Ecol Sociobiol 56:97-105. https://doi.org/10.1007/s00265-004-0765-x

Palagi E (2006) Social play in bonobos (Pan paniscus) and chimpanzees (Pan troglodytes): implications for natural social systems and interindividual relationships. Am J Phys Anthropol 129:418426. https://doi.org/10.1002/ajpa.20289

Palagi E (2008) Sharing the motivation to play: the use of signals in adult bonobos. Anim Behav 75:887-896. https://doi.org/10. 1016/j.anbehav.2007.07.016

Palagi E (2009) Adult play fighting and potential role of tail signals in ringtailed lemurs (Lemur catta). J Comp Psychol 123:1-9. https://doi.org/10.1037/0735-7036.123.1.1

Palagi E (2018) Not just for fun! Social play as a springboard for adult social competence in human and non-human primates. Behav Ecol Sociobiol 72:90. https://doi.org/10.1007/ s00265-018-2506-6

Palagi E, Bergman TJ (2021) Bridging captive and wild studies: behavioural plasticity and social complexity in Theropithecus gelada. Animals 11:3003. https://doi.org/10.3390/ani11103003

Palagi E, Mancini G (2009) Social play and unit membership in immature geladas (Theropithecus gelada). Int Zoo News 56(6):336-341

Palagi E, Mancini G (2011) Playing with the face: Playful facial "chattering" and signal modulation in a monkey species (Theropithecus gelada). J Comp Psychol 125:11-21. https://doi.org/ 10.1037/a0020869

Palagi E, Antonacci D, Cordoni G (2007) Fine-tuning of social play in juvenile lowland gorillas (Gorilla gorilla gorilla). Dev Psychobiol 49:433-445. https://doi.org/10.1002/dev.20219

Palagi E, Norscia I, Spada G (2014) Relaxed open mouth as a playful signal in wild ring-tailed lemurs. Am J Primatol 76:1074-1083. https://doi.org/10.1002/ajp.22294

Palagi E, Nicotra V, Cordoni G (2015) Rapid mimicry and emotional contagion in domestic dogs. R Soc Open Sci 2:150505. https:// doi.org/10.1098/rsos.150505

Palagi E, Burghardt GM, Smuts B, Cordoni G, Dall'Olio S, Fouts HN, Rehakova-Petru M, Siviy SM, Pellis SM (2016) Rough-andtumble play as a window on animal communication. Biol Rev 91:311-327. https://doi.org/10.1111/brv.12172

Palagi E, Leone A, Demuru E, Ferrari PF (2018) High-Ranking Geladas Protect and Comfort Others After Conflicts. Scientific Reports 8(1). https://doi.org/10.1038/s41598-018-33548-y

Palagi E, Marchi E, Cavicchio P, Bandoli F (2019a) Sharing playful mood: rapid facial mimicry in Suricata suricatta. Anim Cogn 22:719-732. https://doi.org/10.1007/s10071-019-01269-y
Palagi E, Norscia I, Pressi S, Cordoni G (2019b) Facial mimicry and play: a comparative study in chimpanzees and gorillas. Emotion 19:665-681. https://psycnet.apa.org/doi/10.1037/emo0000476

Palagi E, Celeghin A, Tamietto M, Winkielman P, Norscia I (2020) The neuroethology of spontaneous mimicry and emotional contagion in human and non-human animals. Neurosci Biobehav Rev 111:149-165. https://doi.org/10.1016/j.neubiorev.2020.01.020

Pellegrini AD (2009) The role of play in human development. Oxford University Press, New York

Pellegrini AD, Smith PK (1998) Physical activity play: the nature and function of a neglected aspect of play. Child Dev 69:577-598. https://doi.org/10.1111/j.1467-8624.1998.tb06226.x

Pellis SM, Burghardt GM (2017) Play and exploration. In: Call J, Burghardt GM, Pepperberg I, Snowdon C, Zentall T (eds) APA handbook of comparative psychology, vol. 1: basic concepts, methods, neural substrate, and behavior. American Psychological Association, Washington, pp 699-722

Pellis SM, Iwaniuk AN (2000) Adult-adult play in primates: comparative analyses of its origin, distribution and evolution. Ethology 106:1083-1104. https://doi.org/10.1046/j.1439-0310.2000. 00627.x

Pellis SM, Pellis VC (2009) The playful brain: venturing to the limits of neuroscience. Oneworld Publications, Oxford

Pellis SM, Pellis VC (2017) What is play fighting and what is it good for? Learn Behav 45:355-366. https://doi.org/10.3758/ s13420-017-0264-3

Pellis SM, Pellis VC, Bell HC (2010a) The function of play in the development of the social brain. Am J Play 2:278-296

Pellis SM, Pellis VC, Reinhart CJ (2010b) The evolution of social play. In: Worthman C, Plotsky P, Schechter D, Cummings C (eds) Formative experiences: the interaction of caregiving, culture, and developmental psychobiology. Cambridge University Press, Cambridge, pp 404-431

Pellis SM, Pellis VC, Reinhart CJ, Thierry B (2011) The use of the bared-teeth display during play fighting in Tonkean macaques (Macaca tonkeana): sometimes it is all about oneself. J Comp Psychol 125:393-403. https://doi.org/10.1037/a0024514

Pereira ME, Kappeler PM (1997) Divergent systems of agonistic behaviour in lemurid primates. Behaviour 134:225-274

Preuschoft S (1992) Laughter and smile in Barbary macaques, Macaca sylvanus. Ethology 91:220-236. https://doi.org/10.1111/j.14390310.1992.tb00864.x

Preuschoft S (1995) "Smiling" and "laughter" in Tonkean macaques (Macaca tonkeana)? In: Preuschoft S (ed) "Laughter" and "smiling" in macaques: an evolutionary perspective. Tessel Offset BV, Utrecht, pp 137-170

Provine RR (1996) Ticklish talk: a letter to the editor and reply. Am Sci 84:100-101

Provine RR (2004) Laughing, tickling, and the evolution of speech and self. Curr Dir Psychol Sci 13:215-218. https://doi.org/10.1111/j. 0963-7214.2004.00311.x

R Core Team (2019) R: a language and environment for statistical computing. R Foundation for Statistical Computing, Vienna. http:// www.R-project.org

Scopa C, Palagi E (2016) Mimic me while playing! Social tolerance and rapid facial mimicry in macaques (Macaca tonkeana and Macaca fuscata). J Comp Psychol 130:153-161. https://doi.org/ $10.1037 /$ com0000028

Shimooka Y, Nakagawa N (2014) Functions of an unreported "rockingembrace" gesture between female Japanese Macaques (Macaca fuscata) in Kinkazan Island, Japan. Primates 55:327-335. https:// doi.org/10.1111/brv.12576

Snyder-Mackler N, Beehner JC, Bergman TJ (2012) Defining higher levels in a gelada multilevel society. Int J Primatol 33:10541068. https://doi.org/10.1007/s10764-012-9584-5 
Spinka M, Newberry RC, Bekoff M (2001) Mammalian play: training for the unexpected. Q Rev Biol 76:141-168. https://doi.org/10. $1086 / 393866$

Tacconi G, Palagi E (2009) Play behavioural tactics under space reduction: social challenges in bonobos, Pan paniscus. Anim Behav 78:469-476. https://doi.org/10.1016/j.anbehav.2009.06.004

Taylor D, Hartmann D, Dezecache G, Wong ST, Davila-Ross M (2019) Facial complexity in sun bears: exact facial mimicry and social sensitivity. Sci Rep 9:4961. https://doi.org/10.1038/ s41598-019-39932-6

Thierry B (1984) Clasping behaviour in Macaca tonkeana. Behaviour 89:1-28. https://doi.org/10.1163/156853984X00010

Thierry B (1985) Social development in three species of macaque (Macaca mulatta, M. fascicularis, $M$. tonkeana): a preliminary report on the first ten weeks of life. Behav Process 11:89-95. https://doi.org/10.1016/0376-6357(85)90105-6

Thierry B (1986) A comparative study of aggression and response to aggression in three species of macaque. In: Else JG, Lee PC (eds) Primate ontogeny, cognition and social behaviour. Cambridge University Press, Cambridge, pp 307-313

van Hooff JARAM (1962) Facial expressions in higher primates. Symp Zool Soc Lond 8:67-125

van Hooff JARAM (1989) Laughter and humor, and the "duo-induo" of nature and culture. In: Walter AK (ed) The nature of culture. Brockmeyer, Bochum, pp 120-149 van Hooff JARAM, Preuschoft S (2003) Laughter and smiling: the intertwining of nature and culture. In: de Waal FBM, Tyack PL (eds) Animal social complexity. Harvard University Press, Cambridge, pp 260-287

Waller BW, Dunbar RIM (2005) Differential behavioural effects of silent bared teeth display and relaxed open mouth display in chimpanzees (Pan troglodytes). Ethology 111:129-142. https:// doi.org/10.1111/j.1439-0310.2004.01045.x

Ward C, Bauer EB, Smuts BB (2008) Partner preferences and asymmetries in social play among domestic dog, Canis lupus familiaris, littermates. Anim Behav 76:1187-1199. https://doi.org/10. 1016/j.anbehav.2008.06.004

Wickham H (2016) Programming with ggplot2. In ggplot2 (pp. 241253). Springer, Cham.

Winkler SL, Bryant GA (2021) Play vocalisations and human laughter: a comparative review. Bioacoustics 30:499-526. https://doi.org/ 10.1080/09524622.2021.1905065

Zanoli A, Gamba M, Lemasson A, Palagi E, Norscia I (2021) Looking into each other's eyes makes it better: eye-to-eye contact enhances sexual interactions in wild geladas. Anim Behav 177:269-276. https://doi.org/10.1016/j.anbehav.2021.05.011

Publisher's note Springer Nature remains neutral with regard to jurisdictional claims in published maps and institutional affiliations. 